\title{
Research on reducing burnout in health care workers in critical situations such as the COVID-19 outbreak
}

\author{
Mohammad Babamiri ${ }^{\mathrm{a}}$, Nasim Alipour ${ }^{\mathrm{b}}$ and Rashid Heidarimoghadam ${ }^{\mathrm{b}, *}$ \\ ${ }^{a}$ Social Determinant of Health Research Center, Department of Ergonomics, School of Public Health, \\ Hamadan University of Medical Sciences, Hamadan, Iran \\ ${ }^{\mathrm{b}}$ Department of Anesthesiology, School of Paramedicine, Hamadan University of Medical Sciences, \\ Hamadan, Iran
}

Received 23 April 2020

Accepted 25 April 2020

After the outbreak of the coronavirus in China in 2019 (COVID-19), and then the spread to many other countries, all efforts by healthcare providers around the world focused on the disease [1]. In this case, doctors and nurses are at the front line of the fight against the disease. During infectious disease outbreaks doctors, nurses, and other health workers are expected to take the risk of contracting the disease and working long hours, even if they do not have enough protective equipment. According to available information, a large number of health workers have been infected with the COVID-19 so far, and many have lost their lives [2]. In this situation, the stress of the health care staff increases [3]. The main causes of stress in these people are increased workload, sleep disturbance, fatigue and the possibility of getting infected [2]. Although stress, fatigue, and increased workload can have a variety of consequences, such as musculoskeletal disorders [4], one of the most likely negative consequences of these conditions is an increase in burnout in health care workers. Increased burnout has also been shown to

\footnotetext{
*Address for correspondence: Rashid Heidarimoghadam, Department of Anesthesiology, School of Paramedicine, Hamadan University of Medical Sciences, Hamadan, Iran. E-mail: dr_haidari @yahoo.com.
}

have long-term consequences in previous pandemics [5]. Therefore, in these conditions, burnout is one of the most important factors that should be considered by occupational health professionals. Because burnout symptoms are enduring in time and not only threaten the health of healthcare staff, they also make health workers reluctant to work and thus reduce the quality of services provided to patients. Now it is time for occupational health professionals to apply existing preventive strategies to reduce strain and stress in order to reduce burnout of frontline health workers against COVID-19 and to test these preventive strategies, even more so as such approaches were rarely tested in critical situations (such as the COVID-19 outbreak). Interventions to reduce burnout are either person-directed or organization-directed. However, these two types of interventions differ in terms of procedures, target groups, and durability of the results [6]. A systematic review indicated that person-directed interventions (such as cognitive behavioral training and relaxation) may be more effective than organizational-directed interventions (such as task restructuring, decreased job demand, increased job control), specifically among highly stressed healthcare professionals [7]. However, given the current crisis and related time pressure, it may be 
appropriate to prioritize organization-directed interventions as their effects may become visible more quickly. Due to the lack of studies in such exceptional conditions, more scientific evidence is needed. Strengthening this research could also result in providing a clinical practice guideline to reduce burnout in health workers as the frontline soldiers against outbreaks such as SARS and COVID-19.

\section{Conflict of interest}

None to report.

\section{References}

[1] Xu B, Kraemer MU, Gutierrez B, Mekaru S, Sewalk K, Loskill A, et al. Open access epidemiological data from the COVID-19 outbreak. The Lancet Infectious Diseases. 2020.
[2] Moazzami B, Razavi-Khorasani N, Dooghaie Moghadam A, Farokhi E, Rezaei N. COVID-19 and Telemedicine: Immediate action required for maintaining healthcare providers well-being. Journal of Clinical Virology. 2020:104345.

[3] Bansal P, Bingemann TA, Greenhawt M, Mosnaim G, Nanda A, Oppenheimer J, et al. Clinician Wellness During the COVID-19 Pandemic: Extraordinary Times and Unusual Challenges for the Allergist/Immunologist. The Journal of Allergy and Clinical Immunology: In Practice. 2020.

[4] Heidarimoghadam R, Saidnia H, Joudaki J, Mohammadi Y, Babamiri M. Does mental workload can lead to musculoskeletal disorders in healthcare office workers? Suggest and investigate a path. Cogent Psychology. 2019;6(1):1664205.

[5] Maunder RG, Lancee WJ, Balderson KE, Bennett JP, Borgundvaag B, Evans S, et al. Long-term psychological and occupational effects of providing hospital healthcare during SARS outbreak. Emerging infectious diseases. 2006;12(12):1924.

[6] Wiederhold BK, Cipresso P, Pizzioli D, Wiederhold M, Riva G. Intervention for physician burnout: A systematic review. Open Medicine. 2018;13(1):253-63.

[7] Van Mol MM, Kompanje EJ, Benoit DD, Bakker J, Nijkamp MD. The prevalence of compassion fatigue and burnout among healthcare professionals in intensive care units: a systematic review. PloS one. 2015;10(8):e0136955. 